\title{
IMPACT OF UNIVERSITY RE-OPENING ON TOTAL COMMUNITY COVID-19 BURDEN
}

\author{
Lauren E. Cipriano, $\mathrm{PhD}^{1,2}$ \\ Wael M. R. Haddara, MD FRCPC MMEd ${ }^{3,4}$ \\ Gregory S. Zaric, $\mathrm{PhD}^{1,2}$ \\ Eva A. Enns, PhD ${ }^{5}$
}

September 18, 2020

1. Ivey Business School, Western University

2. Department of Epidemiology and Biostatistics, Schulich School of Medicine and Dentistry, Western University

3. Department of Medicine, Schulich School of Medicine \& Dentistry, Western University

4. Division of Critical Care, London Health Sciences Centre

5. Division of Health Policy and Management, University of Minnesota School of Public Health

\section{Corresponding author:}

Lauren Cipriano

Ivey Business School at Western University

1255 Western Road

London ON N6G 0N1

P: $519-661-4181$

E: Icipriano@ivey.uwo.ca

Keywords: hospital capacity planning; infectious disease modeling; novel coronavirus; intensive care capacity; covid-19; covid-19 non-pharmaceutical interventions; covid-19 testing

\section{Funding:}

This work was supported in part by the Gordon and Betty Moore Foundation through Grant GBMF9634 to Johns Hopkins University to support the work of the Society for Medical Decision Making COVID-19 Decision Modeling Initiative (co-PIs: Cipriano and Enns) and by a Western University Catalyst Research Grant (PI: Cipriano). LEC is supported by the David G. Burgoyne Faculty Fellowship. GSZ is supported by the J. Allyn Taylor and Arthur H. Mingay Chair in Management Science.

\section{Acknowledgements:}

The authors are grateful to Dr. Seyed Moghadas, Professor of Applied Mathematics and Computational Epidemiology at York University, Toronto, Ontario for sharing data relating to the contact patterns of long-term care residents. 


\begin{abstract}
Purpose: Post-secondary students have higher than average contacts than the general population due to congregate living, use of public transit, high-density academic and social activities, and employment in the services sector. We evaluated the impact of a large student population returning to a mid-sized city currently experiencing a low rate of COVID-19 on community health outcomes. We consider whether targeted routine or one-time screening in this population can mitigate community COVID-19 impacts.
\end{abstract}

Methods: We developed a dynamic transmission model of COVID-19 subdivided into three interacting populations: general population, university students, and long-term care residents. We parameterized the model using the medical literature and expert opinion. We calibrated the model to the observed outcomes in a mid-sized Canadian city between March 1 and August 15, 2020 prior to the arrival of a relatively large post-secondary student population. We evaluated the impact of the student population $(20,000$ people arriving on September 1$)$ on cumulative COVID-19 infections over the fall semester, the timing of peak infections, the timing and peak level of critical care occupancy, and the timing of reengaged social and economic restrictions. We consider multiple scenarios with different student and general population COVID-19 prevention behaviours as well as different COVID-19 screening strategies in students.

Results: In a city with low levels of COVID-19 activity, the return of a relatively large student population substantially increases the total number of COVID-19 infections in the community. In a scenario in which students immediately engage in a $24 \%$ contact reduction compared to pre-COVID levels, the total number of infections in the community increases by $87 \%$ (from 3,900 without the students to 7,299 infections with the students), with $71 \%$ of the incremental infections occurring in the general population, causing social and economic restrictions to be re-engaged 3 weeks earlier and an incremental 17 COVID-19 deaths. Scenarios in which students have an initial, short-term increase in contacts with other students before engaging in contact reduction behaviours can increase infections in the community by $150 \%$ or more. In such scenarios, screening asymptomatic students every 5 days reduces the number of infections attributable to the introduction of the university student population by $42 \%$ and delays the re-engagement of social and economic restrictions by 1 week. Compared to screening every 5 days, one-time mass screening of students prevents fewer infections, but is highly efficient in terms of infections prevented per screening test performed.

Discussion: University students are highly inter-connected with the city communities in which they live and go to school, and they have a higher number of contacts than the general population. High density living environments, enthusiasm for the new school year, and relatively high rates of asymptomatic presentation may decrease their self-protective behaviours and contribute to increased community transmission of COVID-19 affecting at-risk members of the city community. Screening targeted at this population provides significant public health benefits to the community through averted infections, critical care admissions, and COVID-19 deaths. 


\section{INTRODUCTION}

The COVID-19 pandemic presents a substantial public health challenge for local, national, and international communities because the virus is highly transmissible, ${ }^{1-3}$ including prior to symptom onset, ${ }^{4,5}$ and infections initially present with a wide range of non-specific and sometimes mild symptoms. ${ }^{6,7}$ The relatively high rate of hospitalization and need for critical care among severe cases can quickly overwhelm community health care resources and result in substantial mortality. ${ }^{8,9}$

Many communities initially responded to COVID-19 with school closures and stay-at-home orders, which included closure of university campuses and conversion of all in-person instruction to online formats. Over the summer, universities began announcing plans for the fall term. Some universities opted to operate fully online for the fall. ${ }^{10}$ Others announced plans to partially or fully re-open campus and welcome students back for in-person instruction with COVID-19 mitigation strategies in place. These strategies included polices around mask wearing, limiting large gatherings, access to COVID-19 testing, reduced dormitory occupancy, and accommodations for isolating and quarantining students. ${ }^{11}$ While universities have the autonomy to make decisions about the level of on-campus activities offered to their students, their decisions have implications for the communities in which these campuses are located. University students live, work, and socialize both on and off campus, resulting in significant potential for on-campus COVID-19 outbreaks to spill over into the community and vice versa. ${ }^{12}$

Infectious diseases can spread rapidly through a university campus, as evidenced by outbreaks of serogroup B meningococcal disease, mumps, ${ }^{13}$ and the novel H1N1 influenza virus that emerged in 2009. ${ }^{12,14-16}$ Surges of COVID-19 cases have already been observed on the first campuses to re-open this fall, ${ }^{17}$ prompting many universities to abruptly change their fall semester plans. ${ }^{18}$ After 177 students tested positive for the novel coronavirus linked to at least four separate clusters, the University of North Carolina abruptly moved all undergraduate classes online after only a week of in-person instruction. ${ }^{19}$ High-density housing, including multiple roommates and shared facilities like bathrooms, as well as high levels of social activity puts the university population at particular risk for infectious disease transmission. ${ }^{15}$ Furthermore, past experience with the $2009 \mathrm{H} 1 \mathrm{~N} 1$ pandemic indicates compliance with recommended public health precautions may be sub-optimal; despite public health guidance not to attend classes and other activities while ill during the H1N1 outbreak at a US university, half of students indicated interacting with a symptomatic individual in a classroom and nearly one-quarter indicated interacting with a symptomatic individual at a party or social activity. ${ }^{15}$

Given the unique features of university communities, several studies have modeled COVID-19 transmission dynamics specifically on university campuses and evaluated potential mitigation strategies. ${ }^{18,20-24}$ These studies used mathematical models of viral transmission dynamics, tailored to reflect a university context, in order to evaluate testing and contact tracing strategies, largely focusing on the question of how frequently to test asymptomatic students. All analyses concluded that frequent testing (sometimes multiple times a week) would be needed to contain COVID-19 outbreaks on campus. High frequency testing has been adopted by a number of public and private universities including, for example, the University of Illinois (twice per week by saliva testing ${ }^{25}$ ), Colby College (twice per week by nasopharyngeal swab ${ }^{26}$ ), Cornell University (twice weekly for students and faculty with student contact by self-collected anterior nares sampling ${ }^{27}$ ), and Harvard University (one to three days a week for students, staff, and faculty by saliva testing with frequency depending on types of on-campus activity ${ }^{28}$ ). 
It is made available under a CC-BY-NC-ND 4.0 International license .

However, most universities do not have the resources or infrastructure to support high-frequency testing. ${ }^{26}$

Furthermore, while some of these studies did include infections among students arising from offcampus community contact, these studies did not consider the impact of university student infections and university administration prevention and management decisions on the broader community in which that campus is situated. University students themselves may be at lower risk of severe COVID-19 disease due to age, but high infection rates on campus may spill over into the broader community, whose members are at higher risk for adverse COVID-19 outcomes. It is therefore important to quantify the expected impact of the arrival of a relatively large number of university students on the broader community in terms of incremental infections, hospitalizations, and COVID-19 mortality. Through the many interactions between the student population and the city in which they reside, COVID-19 mitigation policies targeted at university student communities and adopted by university leaders may have substantial public health implications for those in the surrounding community.

We developed a dynamic transmission model of COVID-19 to estimate the health impacts and health care resource demand in a COVID-19 outbreak in a representative mid-sized city with a relatively large destination college campus. We assumed a city experiencing a low level of COVID-19 activity going into the semester and explore how the on-campus arrival of the student population impacts COVID-19 health outcomes in the community. We consider different assumptions about student behaviours related to physical distancing and mask wearing, as well as the mitigating effects of targeted routine and one-time COVID-19 screening in the university population. 


\section{METHODS}

\section{OVERVIEW}

We developed a dynamic compartmental model to simulate infection dynamics and health resource use of a representative mid-sized city with a population of 500,000 going into fall after experiencing low rates of COVID-19 infections in the summer. We divided the population into three sub-populations: long-term care (LTC) residents, university students, and the general population (everyone other than LTC residents and university students). We evaluated COVID-19 health outcomes in the city between August 15 and December 31 (4.5 months) with and without the introduction of 20,000 university students on September 1. We explored how the COVD-19 risk and prevention behaviours of the general population and the student community affect the incremental COVID-19 burden attributable to the arrival of the student population. Under different scenarios of community physical distancing effort and routine testing in students, we calculated the number of infected individuals, peak hospital resource demand, and number of deaths over time. Institutional ethics review was not required for this modeling study as human subjects were not involved.

A schematic of the model is presented in Figure 1. In the model, susceptible individuals may become infected through interaction with infected individuals who may or may not be aware of their infection status. Infection has a pre-symptomatic phase in which an infected individual can transmit the infection to others. ${ }^{4,5,29}$ Individuals may become aware of their infection status through symptom-based surveillance, contact tracing, or routine testing of asymptomatic and mildly symptomatic individuals. Individuals aware of their infection status with mild or moderate symptoms isolate at home to reduce disease transmission. Some patients develop severe symptoms requiring hospitalization or critical symptoms requiring mechanical ventilation (MV) in an intensive care unit or renal replacement therapy (RRT). Patients receive medically indicated care, unless resource demand exceeds capacity. When hospital capacity for a medically indicated resource has been reached, patients receive the next-best available care.

We estimated model parameters, including the duration of time spent in each health state, the infectiousness of COVID-19, demand for hospital resources and disease mortality conditional on disease severity, and the effectiveness of COVID-19 prevention strategies using the peer-reviewed literature, pre-published reports, and expert opinion (Table 1). We calibrated uncertain model inputs to the observed hospitalization and mortality outcomes in London, Ontario, Canada, a mid-size city with a large university population, between March 1 to August 15. Full details about the model structure and input parameter estimates are presented in the Supplemental Methods.

\section{POPULATION}

We first establish the epidemic starting conditions in the city on August 15 before the potential arrival of students for fall semester. Based on calibration to COVID-19 outcomes in London, ON, at the start of the simulation, 40 individuals in the general population had active COVID-19 infections, 13.8 were exposed but not yet infectious, and 2,476 individuals had already recovered; thus, 493,937 individuals were susceptible at the beginning of the simulation. In sensitivity analysis, we vary the number of active COVID-19 infections in the general population at the start of the simulation. 
In our analysis, $0.7 \%$ (3,500 individuals) of the population live in long-term care (LTC). Based on the model calibration we estimated that 75 LTC residents were recovered as of August 15. We assumed that there were no active infections in LTC residents on August 15.

We assume that 20,000 university students arrive on September 1. In the base case, we conservatively assume that no students are infected with COVID-19 upon arrival to campus. We vary this assumption in sensitivity analysis.

\section{CLINICAL OUTCOMES AND CLINICAL RESOURCE USE}

A schematic of the health states and transition times for infected individuals is presented in Appendix Figure 1. We assumed a mean incubation period, the time from exposure to symptom-onset, of 5.6 days (observed median of 5.1 days $[95 \% \mathrm{Cl} 2.2,11.5]) .{ }^{30}$ In total, we estimated the average duration of infectiousness in asymptomatic and mild or moderate infections to be 10 days, including 2.5 days prior to symptom onset in individuals who do become symptomatic. ${ }^{4,31,32}$ We assumed that patients with severe and critical symptoms remain infectious until recovered, but that patient isolation protocols prevent transmission for those admitted to hospital.

We estimated hospital length of stay and mortality based on a report of over 20,000 hospitalized patients in the UK. ${ }^{33}$ We estimated length of stay and mortality for patients receiving critical care using the UK Intensive Care National Audit and Research Centre report describing the care and outcomes of 10,118 critical care COVID-19 patients. ${ }^{34}$ For LTC residents who are and are not hospitalized, we estimated the case fatality rate to be $47.4 \%$ and $25.5 \%$, respectively, based on the observed outcomes in 680 Canadian LTC COVID-19 patients. ${ }^{35}$ Combining the assumptions about disease severity and severityspecific mortality rates, the overall infection fatality rate in our model was $25.1 \%$ for LTC residents, $1.3 \%$ for the general population, and $0.06 \%$ for university students. Among hospitalized cases, the fatality rate was $24.2 \%$ for the general population, and $5.2 \%$ for university students.

We did not consider mortality from causes other than COVID-19 in the model.

\section{CONTACT STRUCTURE}

General population: Based on an extrapolation of the 2008 POLYMOD study in Europe to reflect network structure of the Canadian population, the average number of contacts per person in Canada is 12.6 per day, of which 1.0 contacts is aged $20-24 .{ }^{36}$ Assuming that the university student population adds 20,000 individuals aged 20-24 to a community with an otherwise typical Canadian age distribution, university students would comprise $38 \%$ of the population of people aged 20 to 24 in the community. As a result, we assume that a person in the 'general population' has contact with 0.38 university students per day. We calculated the average number of LTC contacts by calculating the number that would balance the staff and visitor contacts estimated for LTC residents, resulting in 0.1 LTC contacts per person in the general population.

Long-term care residents: We estimated that there are 19.9 resident-resident contacts per day ( $95 \% \mathrm{Cl}$ : $11.3-28.5)$ and 13.7 resident-staff contacts per day $(95 \% \mathrm{Cl}: 11.4,15.9)$ using a Canadian study of longterm care residents and staff (personal communication: S. Moghadas). ${ }^{37,38}$ This study did not capture 
resident-visitor contacts; we assumed 0.48 visitors per day based on the distribution of visit frequency in the 2012 Ohio Nursing Home Family Satisfaction Survey. ${ }^{39}$ Thus, in total, LTC residents have 14.2 contacts with the general population each day. We assumed no direct contact with university students.

University students: In our base case analysis, we assume that students have 23.7 contacts per day, based on a study at the University of Antwerp, ${ }^{40}$ and that $60 \%$ of those contacts are with other university students based on the age distribution of student's reported contacts, ${ }^{40,41}$ with the remainder being with members of the 'general population' which includes staff and faculty of the university. Because studies evaluating university student contact patterns often occur during late fall and winter months, the contact patterns identified may not be fully representative of student contact rates at other times of the year. In sensitivity analysis we explored higher rates of student-student contacts in the first few weeks of the semester.

\section{INFECTION RISK AND DISEASE TRANSMISSION}

Using exponential regression, we empirically estimated a basic reproduction number, $R_{0}$, of 3.0 in the general population based on Ontario's reported cases between March 7 to March 22. ${ }^{42}$ Using an average duration of infectiousness of 10 days and an average number of close contacts per person of $12.6,{ }^{36}$ we calculate the probability of transmission between a susceptible and an infected person in close contact, in the absence of any interventions, to be 0.024 .

Interventions such as physical distancing, which reduces the average number of contacts between susceptible and infected people, and mask wearing, which reduces the probability of disease transmission between contacts, can reduce the expected number of infections. We assume the effectiveness of cloth masks in reducing disease transmission is $40 \%$ based on a German study evaluating the effectiveness of real-world mask use. ${ }^{43}$ For people who are aware of their infection status and in home isolation, we assume a $90 \%$ reduction in contacts, which is at the high end of observed adherence to quarantine instructions in past epidemics. ${ }^{44,45}$

We subdivided the general population into two groups based on their intensity of COVID-19 prevention behaviours. Based on behaviours reported in an Angus Reid poll of Canadians, taken in the first week of August, ${ }^{46}$ we estimated that 'high-intensity physical distancers', representing $50 \%$ of the general population initially, reduce their average number of contacts by $75 \%$ (from 12.6 to 3.2 contacts per day) and that $86 \%$ of their remaining contacts are protected by a cloth mask. We assumed that the remainder of the population are not reducing their contacts, but are using a cloth mask to protect $38 \%$ of those contacts. ${ }^{46}$ In the base case, we assumed that university students initially reduce their contacts by $24 \%$ (from 23.7 to 18.0 contacts), which approximates a $75 \%$ reduction in contacts for the $32 \%$ of 18 24 year-olds who reported substantial COVID-19 prevention effort in the Angus Reid poll $(32 \% \times 75 \%=$ $24 \%$ reduction). In this same survey, $57 \%$ of $18-24$ year-olds reported wearing a mask indoors with people outside their household and we use this as the base case level of mask wearing in the university student population. ${ }^{46}$

Responsive behaviour triggers: We assumed that the general population and university students respond to COVID-19 outcomes in the community. In practice, this response may be voluntarily adopted due to public concern over reported increases in COVID-19 cases, hospitalizations, and/or deaths or 
imposed through policies that re-establish the social and economic restrictions utilized in the earlier phases of the pandemic. We included two triggers that would cause both the general population and university students to increase their adoption of protective behaviors: a high level of COVID-19 patients in critical care and a high number of COVID-19 deaths.

The critical care trigger was set based on critical care capacity. The overall critical care capacity in Ontario is 14.2 beds per 100,000 population. ${ }^{47}$ Thus, in a city of 500,000 , normal critical care capacity would be about 70 beds. While additional capacity can be created by seconding resources and personnel from other hospital services, ${ }^{48}$ based on expert opinion, substantial reductions in the provision of other types of health care (such as cancelling elective surgeries) would need to be undertaken if more than 30 critical care beds were used by COVID-19 patients. Therefore, we set one of the responsive behaviour triggers to activate when there are 15 COVID-19 patients in critical care, representing $50 \%$ of the capacity available to COVID-19 patients without modifying access to other health care services.

In the base case, the proportion of the general population who are 'high intensity physical distancers' increases by $0.5 \%$ each day if the number of COVID-19 patients in critical care exceeds 15 and by an additional $1.0 \%$ each day if the number of COVID-19 deaths in the past 10 days exceeds 10 , up to a maximum of $80 \%$ participation in high-intensity physical distancing. Similarly, we assume students' reduction in contacts increases at the same rate in response to the same triggers, but up to a maximum of a $50 \%$ reduction in contacts ( 23.7 contacts to 11.9 contacts).

\section{DIAGNOSIS BY SYMPTOM-BASED SURVEILLANCE, CONTACT TRACING, AND ROUTINE TESTING}

For the general population and university students, we assumed the minimum time from symptom onset to diagnosis to be 2.1 days, which is consistent with the minimum time needed to self-assess, seek medical attention, and receive diagnostic results. ${ }^{7}$ The observed median time to diagnosis through symptom-based surveillance alone was 4.6 days $(95 \% \mathrm{Cl}: 4.2,5.0)$ and symptom-based surveillance in combination with contact tracing efforts was 2.9 days $(95 \% \mathrm{Cl} 2.4,3.4)$ in Shenzhen, China. ${ }^{49}$ From this, we estimated that symptom-based surveillance and contact tracing results in a daily probability of diagnosis of $15.8 \%$ for symptomatic infections and a daily probability of detection (from contact tracing) of $4.1 \%$ for asymptomatic infections. This combination of assumptions resulted in approximately $22 \%$ of infected individuals being identified, consistent with the overall rates of diagnosis implied by preliminary serology data in Ontario. ${ }^{50}$

We considered policy alternatives of routine screening for COVID-19 in university students at various screening frequencies, including every $14,10,7,5$, and 3 days. We also considered the value of a onetime universal screening three weeks after student arrival. We identified the date of the one-time testing by identifying the date that minimized the number of total infections over the semester. We assumed that testing will be performed with the standard COVID-19 nasopharyngeal swab followed by PCR analysis with a test sensitivity of $72.1 \% .^{51,52}$ 


\section{RESULTS}

City epidemic outcomes without the introduction of the university student population

Without the introduction of the student population, the base case assumptions for the general population and LTC residents leads to a total of 3,900 infections over 4.5 months (August 15 to December 31). In this scenario, infections, hospitalizations, and daily deaths do not peak until the new year (Appendix Table 1). Demand for critical care (mechanical ventilation or renal replacement therapy) peaks at 27 beds early in the new year, and a total of 31 COVID-19 deaths occur between August 15 and December 31 (60 deaths by January 31, 2021). The timing and magnitude of the city's COVID-19 outbreak, excluding any impacts from students, is determined by the initial number of COVID-19 infections in the community, the level of participation in physical distancing, the responsiveness of the community to increasing critical care cases and COVID-19 deaths, and the proportion of contacts that are protected with mask wearing (Appendix Figures 5-7).

\section{Effect of introducing 20,000 university students to the community}

In the base case, we conservatively assumed that students would bring no undiagnosed infections of COVID-19 to the community and would immediately engage in physical distancing efforts that resulted in a similar average contact reduction to the general population (reduction of $24 \%$, from average of 23.7 contacts to 18.0 contacts). Even so, university students continue to have a higher average number of contacts than members of the general population. As a result, in this base case scenario, the introduction of students to the community increases the total number of infections by 3,399 infections, representing an $87 \%$ increase (from 3,900 to 7,299) (Figure 2). Only $28 \%$ (960) of these incremental infections occur in the student population (representing $4.8 \%$ of students becoming infected). Of the remaining $72 \%$ of incremental infections, 2,428 occur in the general population $(0.5 \%$ of the susceptible general population), and 11 occur in long-term care ( $0.3 \%$ of the susceptible LTC population). The larger absolute increase in infections in the general population occurs due to the connectivity of the university community with the general population and the relative size of the general population. The increase in infections among LTC residents, despite our assumption that there are no direct contacts between university students and LTC residents, occurs due to the increase in infections in the general population. The higher number of infections results in an increase in hospitalizations, demand for critical care, and COVID-19 deaths. Peak critical care occupancy increases by $48 \%$ (from 27 to 40 beds). These outcomes include the mitigation effects of the responsive behaviour of the community to seeing high levels of COVID-19 hospitalizations. The introduction of students to the community also moves up the timing of responsive behaviours, with the threshold of 15 COVID-19 patients in critical care being reached 3 weeks earlier (Appendix Table 2).

If some students arrive exposed or asymptomatically infected, the total number of infections occurring over the course of the semester increases. For example, if 10 students arrive infected, the number of infections increases by 1,047 over the base case. The impact of students arriving already exposed or infected in the community is most substantial on the timing of peak infections, peak hospitalizations, peak critical care utilization, and the timing of responsive behaviour triggers. Compared to the scenario without the introduction of the student population, responsive behaviours are triggered 6.5 weeks earlier if 10 students are infected when they arrive (Appendix Table 3). 


\section{Initial level of student contact behaviour}

Our estimates of average student contacts per day were based on surveys completed at times other than during the first few weeks of the school year, which normally involve a large number of social activities. Even if muted, the first few weeks of the new academic year may still result in substantially more contacts than a typical pre-COVID era day. Therefore, we explored the consequences associated with students having an increased number of student contacts for one or two weeks upon arrival to the community. For example, if students simply delay implementing physical distancing for two weeks, the total number of infections attributable to the introduction of the students into the community increases by 4,713 infections (from 3,900 to 8,613 infections). In this scenario, the arrival of students would result in a $120 \%$ increase in the number of infections the community. As in the base case, the majority of these incremental infections occur in the general population (Figure 2).

If students have twice the pre-COVID era number of contacts with other students for two weeks (37.9 contacts per day, 28.4 of whom are other students), the total number of infections in the community increases by 6,394 infections representing a $164 \%$ increase in the number of infections the community would expect without the students and leading to an additional 72 COVID-19 deaths (Appendix Figure 8,

Appendix Table 4). Delays in the implementation of contact reductions, or short-term increases in the number of student-student contacts increases demand for critical care resources and shortens the time until critical care beds dedicated to COVID-19 patients exceeds 30 beds (Figure 2B). The impact on total infections is mitigated by the earlier activation of responsive behaviour triggers, which occurs 8.3 weeks after the arrival of the students and 8 weeks earlier than without the arrival of the student population.

\section{Effectiveness of routine asymptomatic screening targeted at students}

Because young people have a high rate of asymptomatic and mild presentation, routine testing of students has been proposed for university campus settings. Testing students every 28 days results in very little reduction in the number of infections but requires a large number of tests (714 students tested per day). Testing every 14 days, as is recommended for staff at long-term care facilities, ${ }^{53}$ reduces the number of infections in the student population from 960 to 735 , a 23\% reduction, and reduces the overall number of infections due to the introduction of the university student population by $22 \%$ (from 3,399 to 2,653) (Figure 3).

More frequent testing reduces infections further. Testing students every 5 days reduces the number of infections among the student population by $44 \%$ (from 960 to 541) and reduces the total number of infections due to the introduction of the university student population to the community by $41 \%$ (from 3,399 to 2,007). Routine testing has greater impact in the scenarios when students engage in a shortterm increase in the number of contacts early in the term. In the scenario in which students double their student contacts for the first two weeks of term, testing every 5 days reduces the number of infections in the student population by $47 \%$ (from 1,990 to 1,047), reduces the total number of infections due to the introduction of the university student population by $42 \%$ (from 6,394 to 3,732 ), and delays the activation of responsive behaviour triggers by 1 week (Appendix Table 5). 
Routine testing of students also averts critical care admissions and COVID-19 mortality in the general population, because approximately two-thirds of averted infections are prevented in the general population (Table 2). In the base case analysis, in which students immediately reduce their contacts compared to a pre-COVID-19, routine screening every 5 days averts 16.5 critical care admissions and 12.8 deaths. In scenarios in which students have short term increases in their contact behaviours or lower levels of contact reduction, routine testing every 5 days averts more than 29 critical care admissions and greater than 20 COVID-19 deaths.

Sensitivity analysis revealed that routine testing of university students was more valuable when students have a higher rate of asymptomatic infections (Table $\mathbf{2}$ ) and in scenarios in which the differences in transmission risk between the university students and the general population were greater. For example, in a scenario in which the city had a high level of engagement in physical distancing routine screening of the student population can avert a large number of infections because in these scenarios the city expects very little COVID-19 transmission without the introduction of the student population (Figure 3C). Conversely, in scenarios in which the city is engaged in a low level of physical distancing and so expects a large number of infections with or without the student population, the difference in risk profile between the city and the university populations decreases, as does the benefits of targeting prevention efforts at the university population.

\section{Effectiveness of one-time screening targeted at students}

Routine testing to identify and isolate asymptomatic infections for the purposes of reducing community transmission risk requires a large number of tests each day and may strain community testing resources. We also evaluated the benefits of a one-time universal screening event occurring three weeks after the students arrive. Compared to routine testing every 5 days, which would require more than 400,000 tests to be performed over the semester, this strategy would only require 20,000 tests. Through the isolation of identified cases, one-time testing is able to immediately decrease the daily number of new infections in the student population and, so, indirectly in the general population (Appendix Figure 9). In the case that students double their contacts with other students for a period of two-weeks, this strategy prevents 361 infections (122 infections in students, 238 infections in the general population, and 1 infection in LTC residents), 4.0 critical care admissions, and 3.1 COVID-19 deaths (Table 2). One-time screening does not significantly impact the timing of peak infections, resource utilization, or the time that responsive behaviour triggers are activated (Appendix Table 5).

\section{Sensitivity analysis}

We performed extensive sensitivity analysis exploring the impact of general population and student population COVID-19 prevention behaviours on the incremental impact of introducing students into the community.

The negative impacts of introducing the student population can be partially mitigated through high uptake of COVID-19 preventive behaviours in the student population including high rates of contact reduction or if the rate of mask wearing significantly exceeds the level reported by 18 to 24 year-olds (Appendix Figure 10, Appendix Table 6). For example, if students immediately reduce their contacts by, 
medRxiv preprint doi: https://doi.org/10.1101/2020.09.18.20197467; this version posted September 18, 2020. The copyright holder for this preprint (which was not certified by peer review) is the author/funder, who has granted medRxiv a license to display the preprint in perpetuity.

It is made available under a CC-BY-NC-ND 4.0 International license .

on average, $30 \%$ (from 23.7 to 16.6 contacts per day) and wear masks to protect $65 \%$ of their remaining contacts, the incremental number of infections attributable to the arrival of the student population can be reduced to 1,698 infections (from 3,900 to 5,598 ), representing only a $44 \%$ increase over the number of infections the community would expect without the students, and delays the activation of responsive behaviour triggers by 1 week.

The magnitude of the impact of the introducing the student population is also determined by the COVID-19 prevention behaviours of the general population. Counter-intuitively, the relative impact of introducing the student population is greatest when the prevention efforts by the general population are high (Appendix Figure 11). For example, when $60 \%$ of the general population are participating in high-intensity physical distancing, without students the number of new infections per day is nearly constant over time, resulting in a very low level of cumulative infections over the semester (total of 543 infections). Introduction of the students results in 939 additional infections, more than doubling the total number of infections expected in the city without the addition of the student population (Appendix Table 2). In such a scenario, because the student population is an important determinant of city outcomes, the impact of routine COVID-19 screening in the student population is greater (Figure 3C). 


\section{DISCUSSION}

In this analysis, we consider the COVID-19 impacts of the re-opening of a destination university in a midsized city with varying epidemiological contexts. Without the return of university students, we devised several scenarios involving moderate to severe fall COVID-19 waves based on difference levels of preventive behaviours in the general population. The return of a large number of students always worsens these waves, even under the conservative assumptions that arriving students do not introduce any new infections to a community and that they immediately adopt substantial COVID-19 prevention behaviours. This is because university students have nearly double the number of contacts as the general population due to residing in shared or congregate living situations, working in the service sector, and higher levels of social activity. In the scenarios we considered, this increase in infections was substantial, potentially doubling of the total number of COVID-19 infections in the city over the fall. Notably, we found that more than two-thirds of the incremental infections attributable to the arrival of the student population occurred in the general population and, as a result, substantially impacted the city's health care resource needs, COVID-19 mortality in the community, and accelerated the need for responsive behaviour which may be in the form of re-engaged social and economic restrictions.

Our base case finding that the return of university students would increase the number of infections by $87 \%$ is likely conservative. In this analysis, we assumed that no students arrive already infected, students do not engage in short term increases in contacts upon arrival, and that students respond to adverse community COVID-19 outcomes by increasing the intensity of their prevention behaviours at the same rate as the general population. At the very least, it may take time for students to fully adopt protective measures; moving into dorms, orientation events, and start of semester social events (even if not officially sanctioned by the university) may result in higher-than-normal levels of contact for at least the first few weeks. In the analyses in which we consider short-term increases in the average number of student-student contacts, we show that a higher level of contact for just the first one or two weeks can dramatically increase the total number of infections experienced by the city over the semester.

Our analysis found that the majority of the increase in infections due to the arrival of students occurred in the general population, not in the student population itself. While university campuses may seem like isolated bubbles, the general community and university students are intertwined, as staff and faculty interact with students on campus and students interact with others off-campus in work, living, and social settings. Previous studies modeling university populations did not account for infections in the broader off-campus community. ${ }^{20-24}$ However, we have shown that including the general population when modeling COVID-19 transmission on university campuses is critical, since this population bears the brunt of the incremental morbidity and mortality burden of COVID-19. As a result, university policies that either discourage student return to the community, ${ }^{54}$ such as offering coursework fully online, or mitigate COVID-19 risks for students returning to campus, such as screening for COVID-19 symptoms and routine COVID-19 testing in asymptomatic individuals, can have substantial impacts on the city's COVID-19 burden. Imposing restrictions on students' off-campus social behavior may be practically difficult, necessitating modified behaviors in the general population in response to university reopening, such as additional reductions in social contacts to balance the increased risk of returning university students. For example, in the base case, the increase in infections due to student arrival could be mitigated if the proportion of the general population engaged in high-intensity physical distancing increased by $4.6 \%$ (from $50 \%$ to $54.6 \%$ ). This illustrates the idea of "risk budgets", where increased risk 
It is made available under a CC-BY-NC-ND 4.0 International license .

in one domain of a community necessitates reducing risk in another to keep COVID-19 impacts below desired thresholds. ${ }^{55}$

Our analysis indicates that routine testing of all students every 5 days can avert a substantial number of infections, critical care admissions, and COVID-19 deaths. In the base case, we estimate that testing every 5 days prevents 16.5 critical care admissions and 12.8 deaths and, in the scenario in which students double their contacts with other students for two weeks, we estimate that testing every 5 days prevents 29.1 critical care admissions and 22.6 deaths. Using the simplifying assumption that all deaths averted will be in 60 -year-olds and a willingness to pay of $\$ 50,000$ per life-year-gained, the economic value of these deaths averted is $\$ 13.4$ million to $\$ 23.6$ million, translating to a value of $\$ 33$ to $\$ 59$ per test. This calculation underestimates the benefits of testing by not accounting for savings due to averted critical care admissions and the community economic benefits of delaying social and economic restrictions; despite this, because we estimate the lab cost of nasopharyngeal testing for COVID-19 at $\$ 80$ per test at our center, high-frequency routine testing is likely only cost effective using batch testing strategies.

Alternatively, one-time universal testing of students after an initial burst of social activity among students may be more feasible operationally and economically. We estimated that this strategy can prevent 360 infections, 4.0 critical care admissions, and 3.1 COVID-19 deaths corresponding to an approximate economic value of $\$ 3.3$ million or $\$ 164$ per test. This strategy is most effective at changing the trajectory of new infections if testing occurs after a short-term period of high social activity and is less effective if students have consistent but lower levels of contact reductions (e.g., immediately reducing their contacts, but by only $15 \%$ instead of the $24 \%$ in the base case).

An important limitation of our analysis is that we assume students with a COVID-19 diagnosis will be willing and able to self-isolate effectively. However, it may be challenging for students to isolate from roommates or refrain from using shared facilities, like bathrooms and kitchens, without dedicated university-organized isolation facilities. ${ }^{56,57}$ Furthermore, adherence to isolation guidance may be low, especially if the majority of infections in university students are asymptomatic or mild. During the H1N1 pandemic, a survey of symptomatic university students found that only $41 \%$ of students followed recommendations to stay home until well. ${ }^{16}$ In the base case, we also assume that students are equally responsive as the general population to COVID-19 outcomes in the community reducing their contacts in response to high numbers of critical care hospitalizations and deaths. In reality, university students may be less aware of the impacts of COVID-19 on hospital resources and less concerned about COVID-19 generally given their lower risk of adverse outcomes. The extent and speed with university students respond to hospitalizations and deaths in the local community will impact the number of infections experienced by the community and the benefits of routine testing in the student population.

Compared to other modeling studies of COVID-19 on university campuses, the total number of infections and the number of infections averted by testing we estimate over the semester are modest. This is because we assume that both university students and the general population will increase their self-protective behavior (physical distancing) in response to high numbers of COVID-19 hospitalizations and deaths, either through individual decision-making or adaptive community policies. These adaptive behaviors are more realistic than assuming a population will maintain the same behavior no matter the severity of local COVID-19 conditions. Thus, in our analysis, testing is being layered onto a robust and reactive mitigation response. 
It is made available under a CC-BY-NC-ND 4.0 International license .

Our model includes only three sub-populations and so does not include many other aspects of agestructured mixing or age-dependant health outcomes. The model does not estimate the impact of COVID-19 patient utilization on the provision or effectiveness of other health care services and the model does not account for death from causes other than COVID-19. ${ }^{58}$ The model includes community transmission by stratified random mixing but does not include additional imported index cases from other cities, which may occur into the general population or the student population, nor does the model include the stochastic consequences of super-spreading events. Especially early on in an epidemic or when cases have been brought to very low levels, dynamics are sensitive to random outcomes in the number of new infections resulting from each case (e.g., 'Patient 31' in South Korea ${ }^{59}$ and 'Patient One' in $\left(\right.$ taly $\left.{ }^{60}\right)$.

\section{Conclusion}

We developed a model-based analysis to estimate the impact of a relatively large student population on the COVID-19 outcomes of a mid-sized city with relatively few cases of COVID-19 prior to the return of students. Our analysis is relevant to a number of mid-sized cities in North America with relatively large university and college populations. Because university students have substantially more contacts than the general population, due to congregate living environments, high-density social activities, and disproportionate employment in the service sector, the introduction of university students substantially increases the number of COVID-19 infections and decreases the time until responsive behaviours are activated. Substantial uncertainty exists in the level of contact reduction that students will choose, or is feasible given their living, transit, and work situations. Public health interventions, such as routine testing, targeted at this population prevents infections in the entire population, improving community health related and unrelated to COVID-19. 
medRxiv preprint doi: https://doi.org/10.1101/2020.09.18.20197467; this version posted September 18, 2020. The copyright holder for this preprint (which was not certified by peer review) is the author/funder, who has granted medRxiv a license to display the preprint in perpetuity.

It is made available under a CC-BY-NC-ND 4.0 International license .

FIGURE 1. Model schematics of (A) COVID-19 health states and (B) close contact interactions between population subgroups. The number of contacts between groups indicated on the schematic represent the average number of contacts per day in a pre-COVID-19 era.

(A)

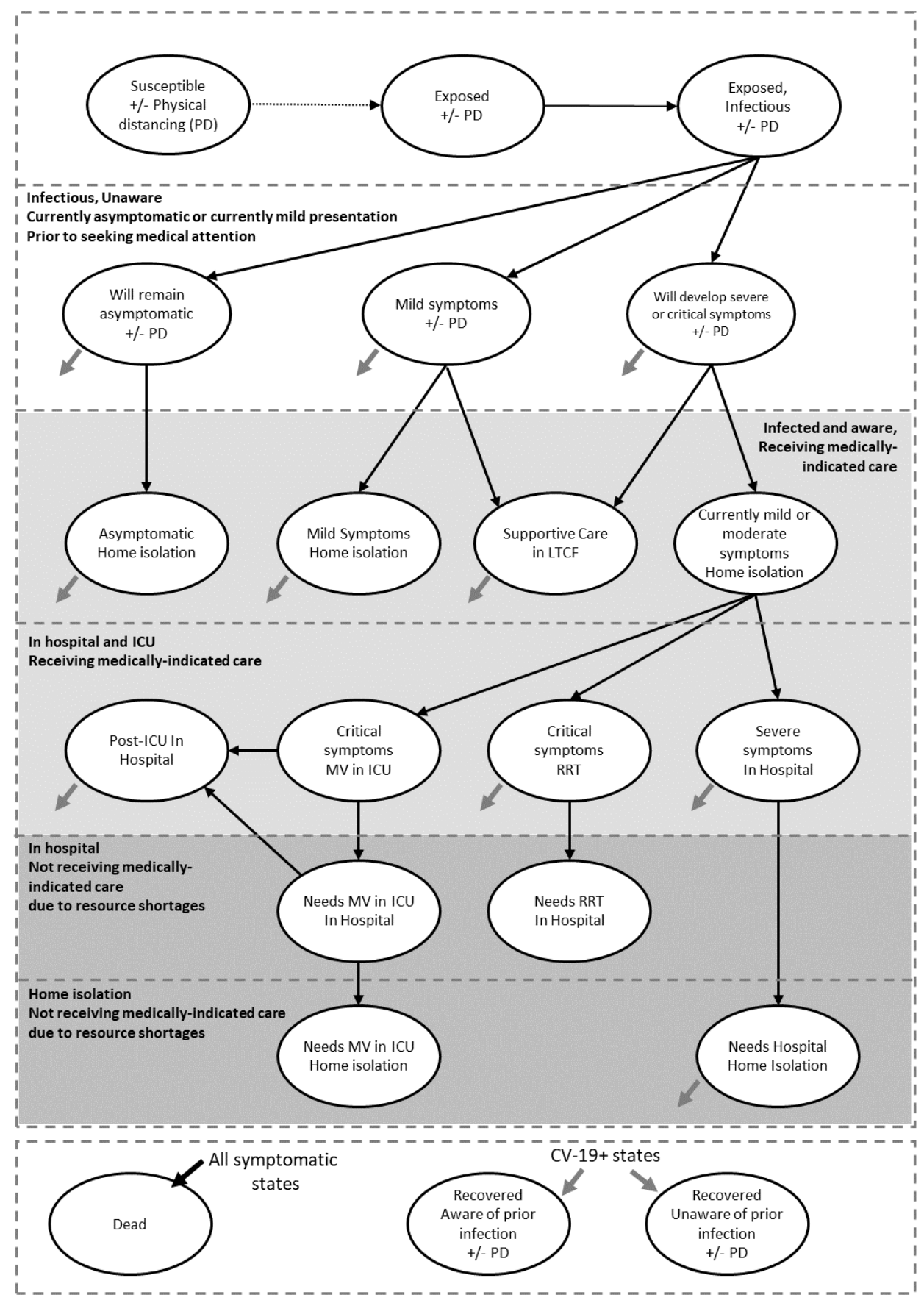


medRxiv preprint doi: https://doi.org/10.1101/2020.09.18.20197467; this version posted September 18, 2020. The copyright holder for this preprint (which was not certified by peer review) is the author/funder, who has granted medRxiv a license to display the preprint in perpetuity.

(B)

It is made available under a CC-BY-NC-ND 4.0 International license .

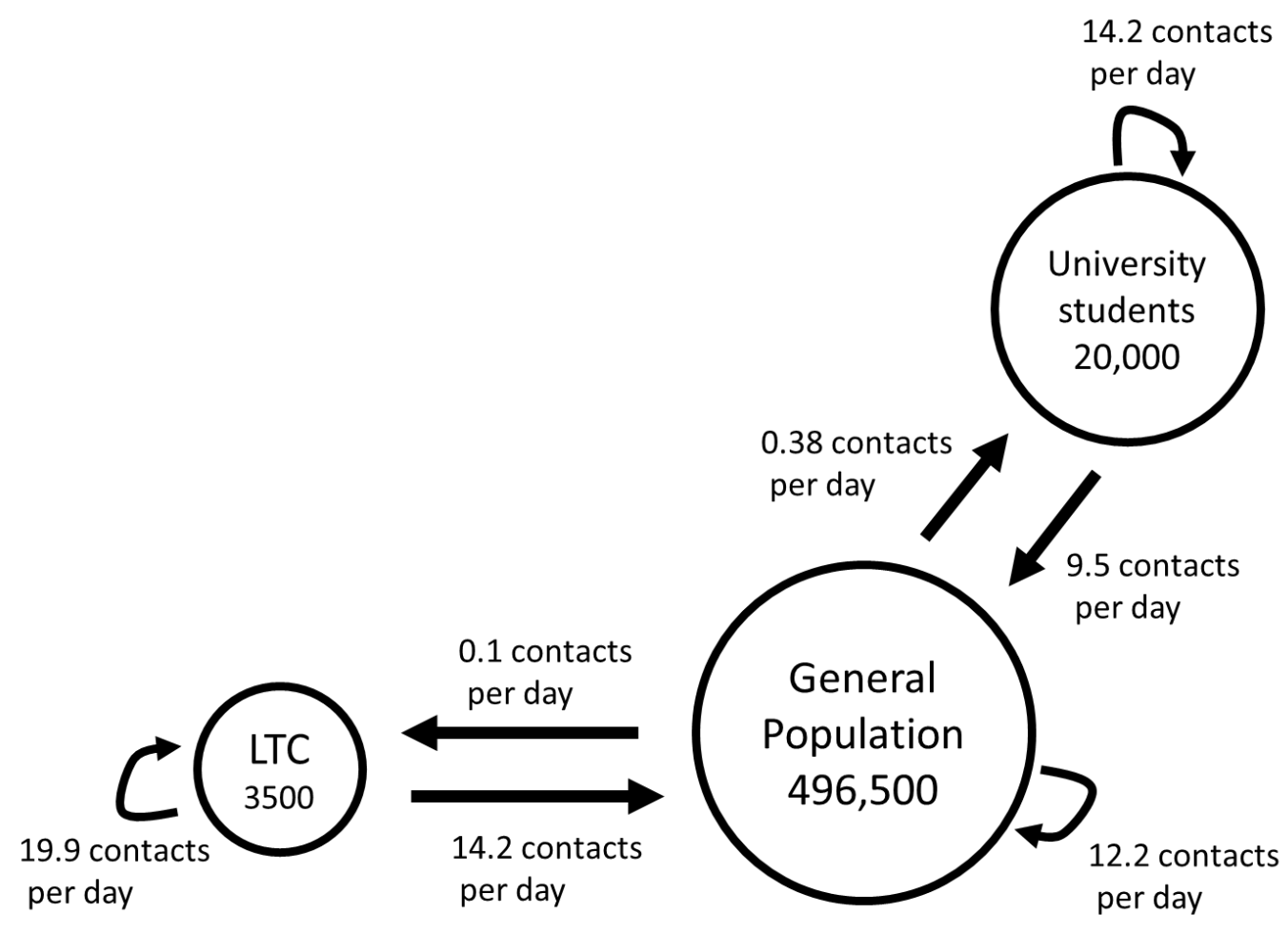


medRxiv preprint doi: https://doi.org/10.1101/2020.09.18.20197467; this version posted September 18, 2020. The copyright holder for this preprint (which was not certified by peer review) is the author/funder, who has granted medRxiv a license to display the preprint in perpetuity.

It is made available under a CC-BY-NC-ND 4.0 International license .

FIGURE 2. Epidemic outcomes in a city of 500,000 with and without the introduction of $\mathbf{2 0 , 0 0 0}$ university students on September 1. Scenarios consider different initial physical distancing behaviours in the university student population. (A) Number of new infections per day; (B) the number of people medically indicated for critical care each day; and, (C) the cumulative number of COVID-19 infections between August 15 and December 31. Numerical results are provided in Appendix Table 4.

(A)

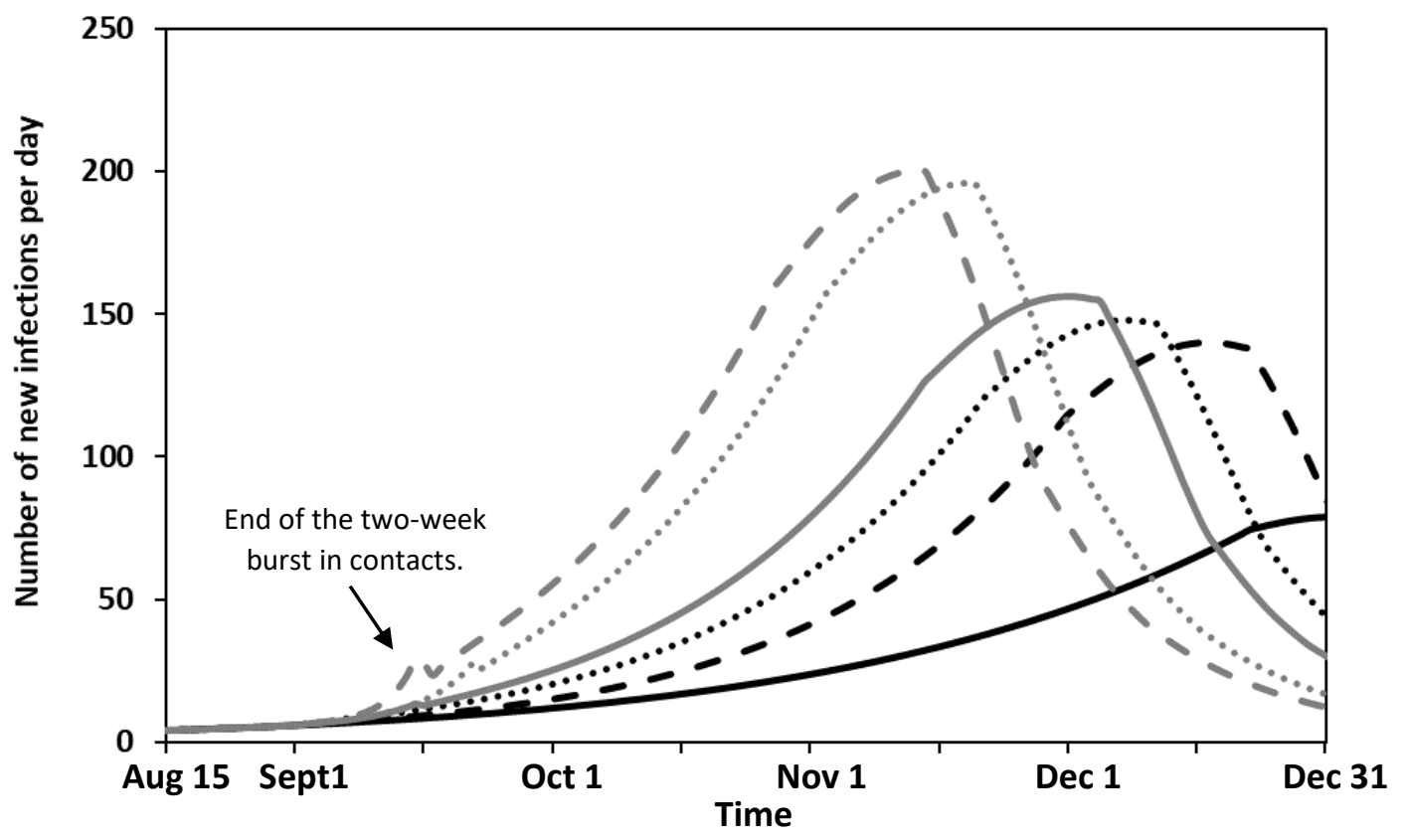


medRxiv preprint doi: https://doi.org/10.1101/2020.09.18.20197467; this version posted September 18, 2020. The copyright holder for this preprint (which was not certified by peer review) is the author/funder, who has granted medRxiv a license to display the preprint in perpetuity.

It is made available under a CC-BY-NC-ND 4.0 International license .

(B)

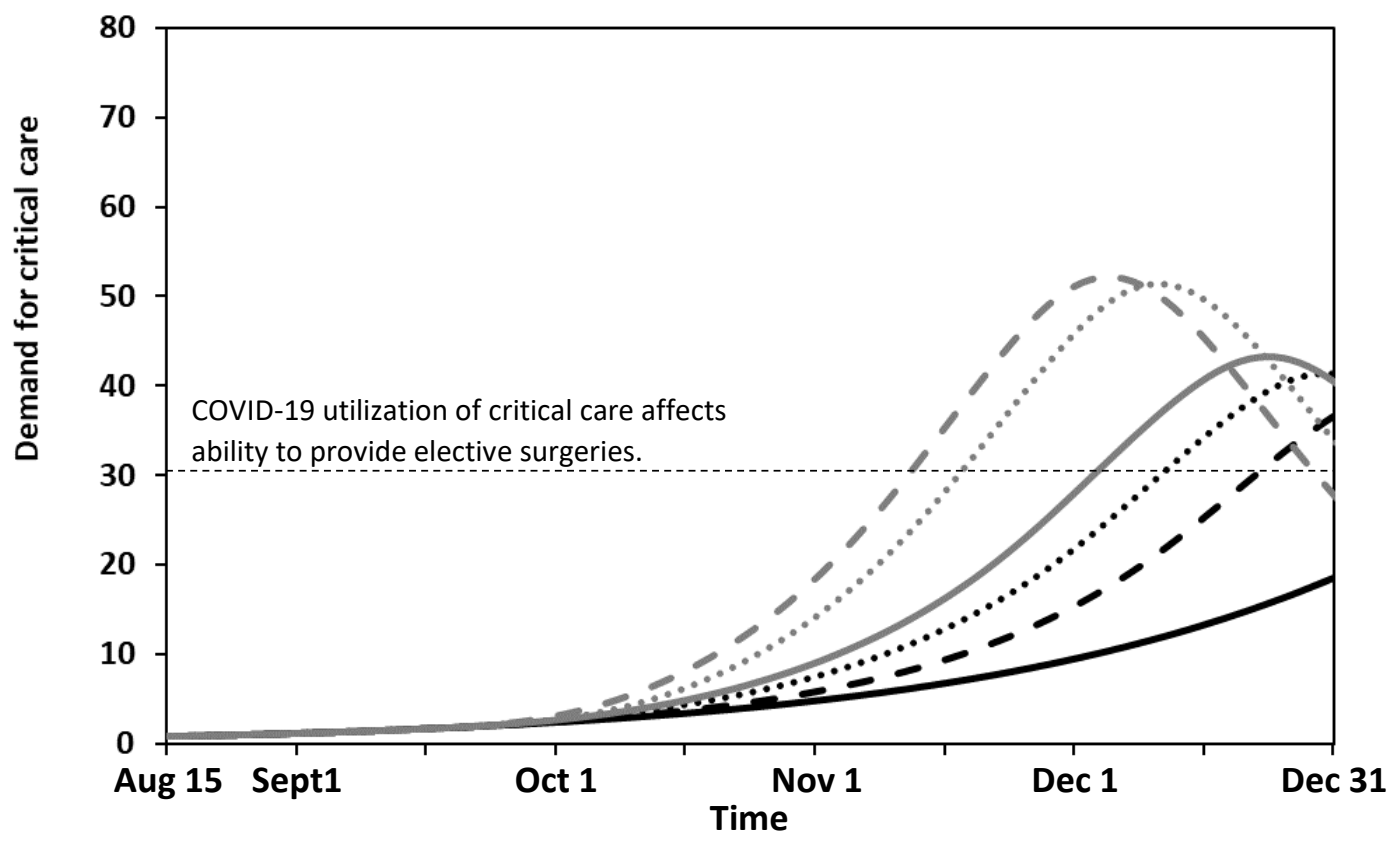

(C)

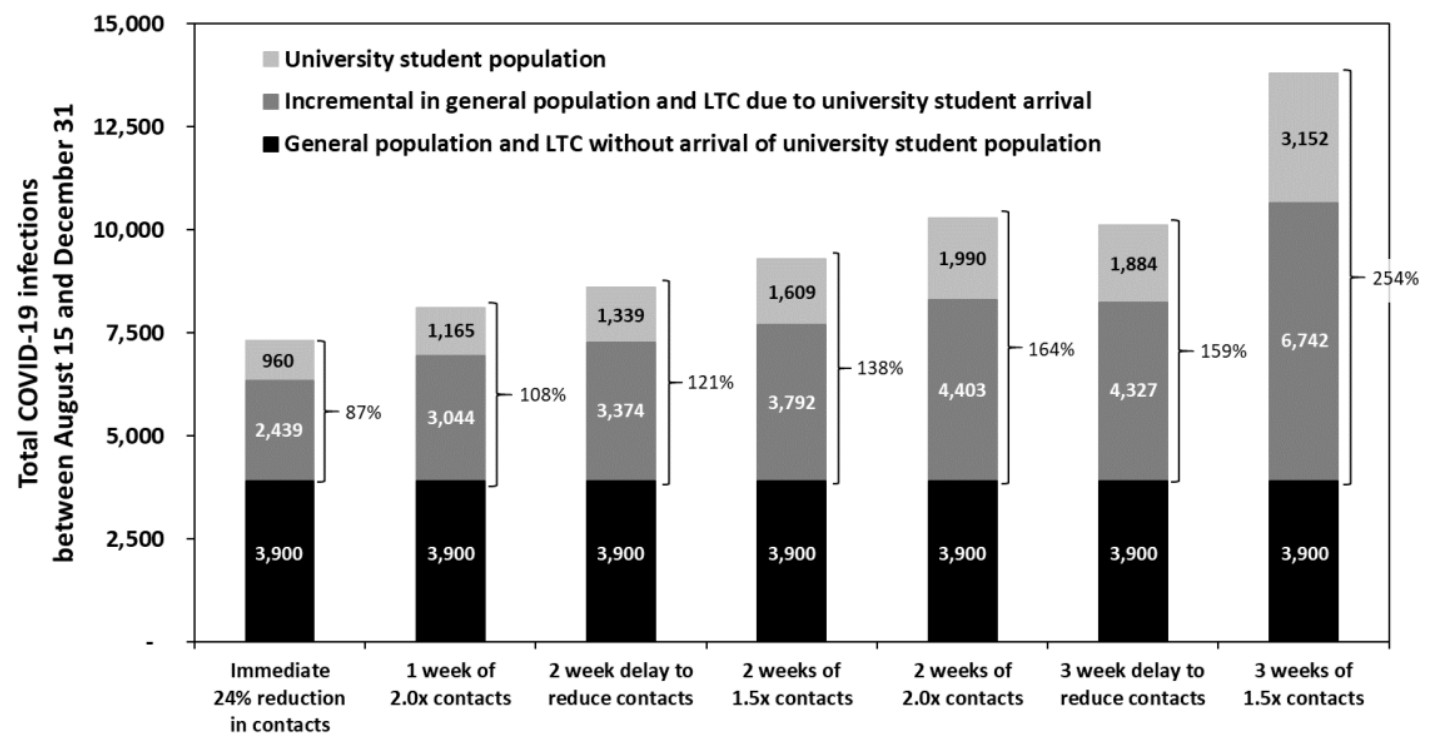


medRxiv preprint doi: https://doi.org/10.1101/2020.09.18.20197467; this version posted September 18, 2020. The copyright holder for this preprint (which was not certified by peer review) is the author/funder, who has granted medRxiv a license to display the preprint in perpetuity.

It is made available under a CC-BY-NC-ND 4.0 International license .

FIGURE 3. Cumulative number of COVID-19 infections between August 15 and December 31 in a city of 500,000 with and without the introduction of 20,000 university students on September 1 . Scenarios in each panel differ in the frequency with which students undergo routine testing for COVID-19. In panel (A), students have an average $24 \%$ reduction in contacts compared to normal student social interaction behaviour (average of 23.7 contacts reduced to 18.0 contacts) immediately upon arrival with no shortterm increase in contacts; in panel (B), students double their contacts with other students for the first two weeks and then implement a $24 \%$ reduction in their contacts; in panel (C), students double their contacts with other students for the first two weeks and then implement a $24 \%$ reduction in contacts and $60 \%$ of the general population is participating in high-intensity physical distancing (compared to $50 \%$ in the base case and other scenarios presented in this figure). Other outcomes for these scenarios are reported in Appendix Table 5.

(A)

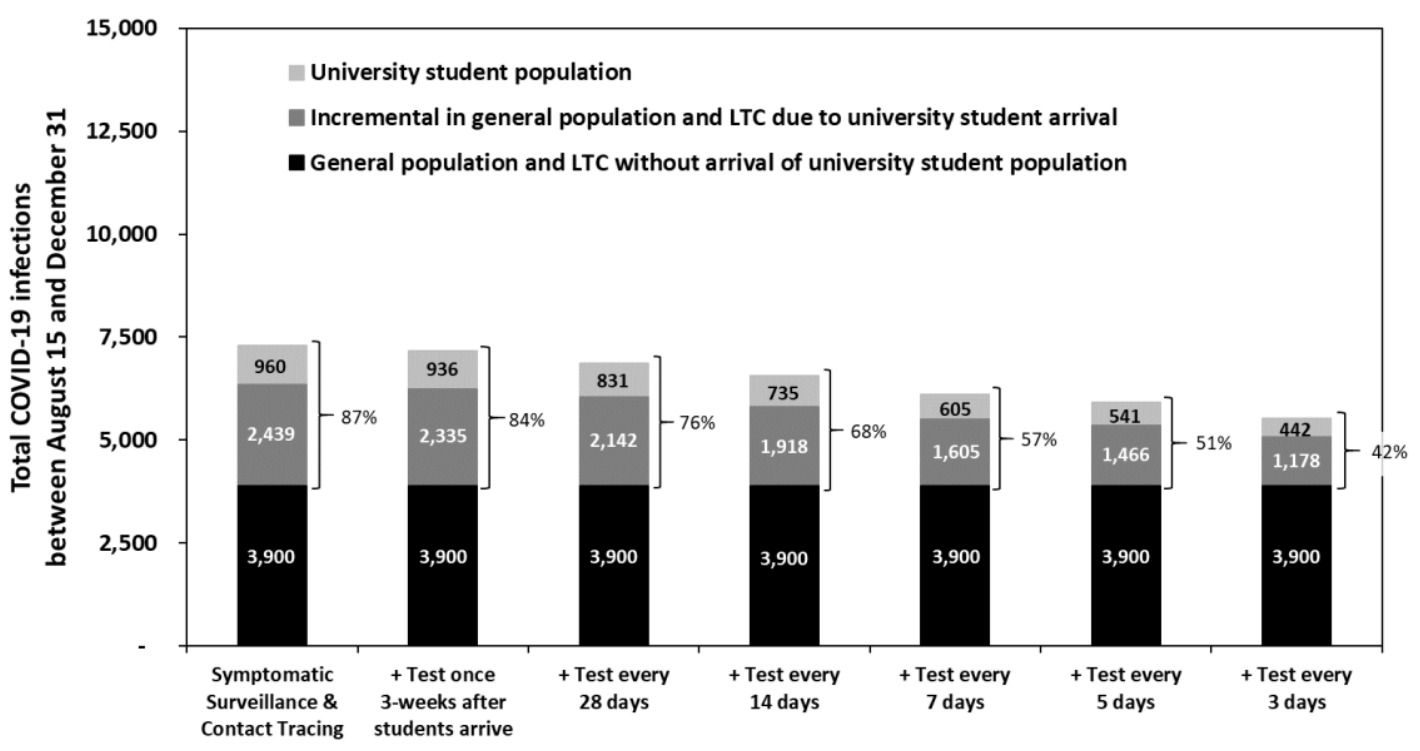

(B)

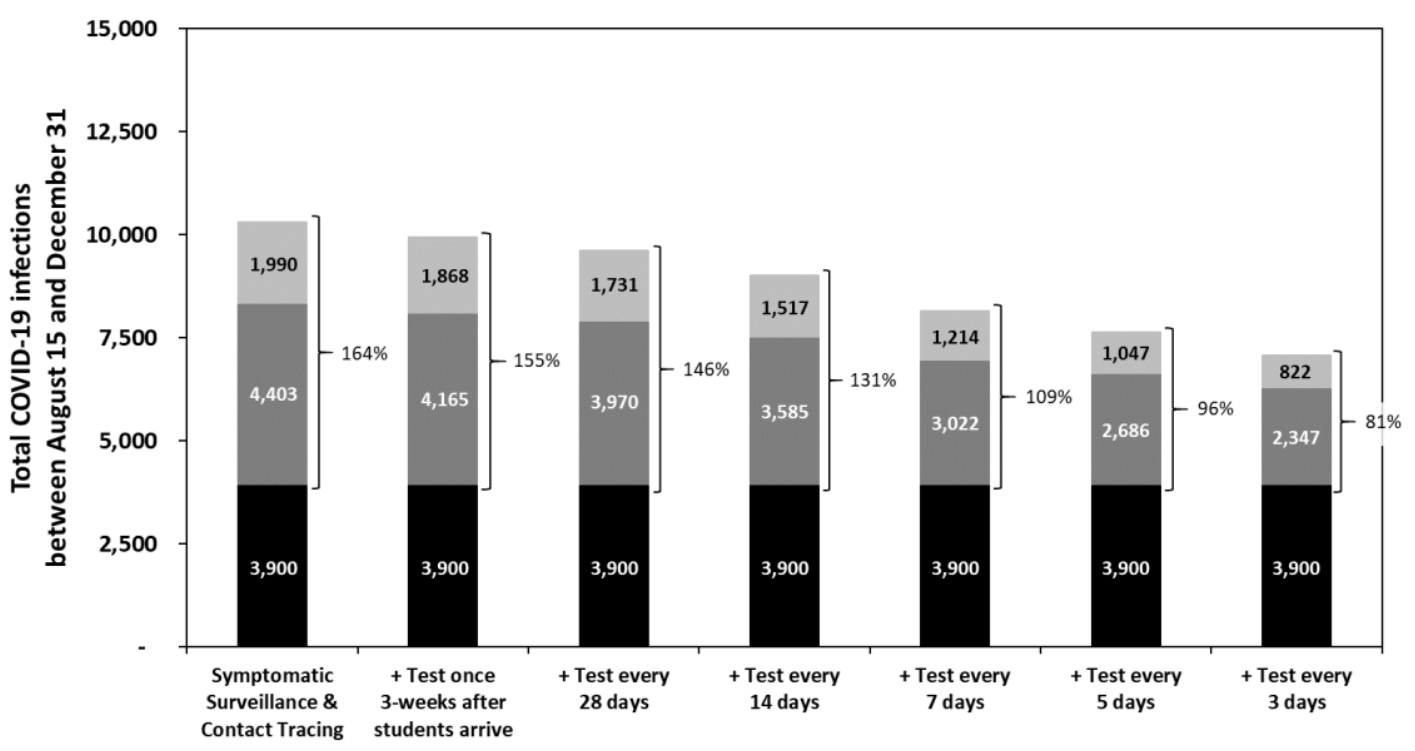


medRxiv preprint doi: https://doi.org/10.1101/2020.09.18.20197467; this version posted September 18, 2020. The copyright holder for this preprint (which was not certified by peer review) is the author/funder, who has granted medRxiv a license to display the preprint in perpetuity.

It is made available under a CC-BY-NC-ND 4.0 International license .

(C)

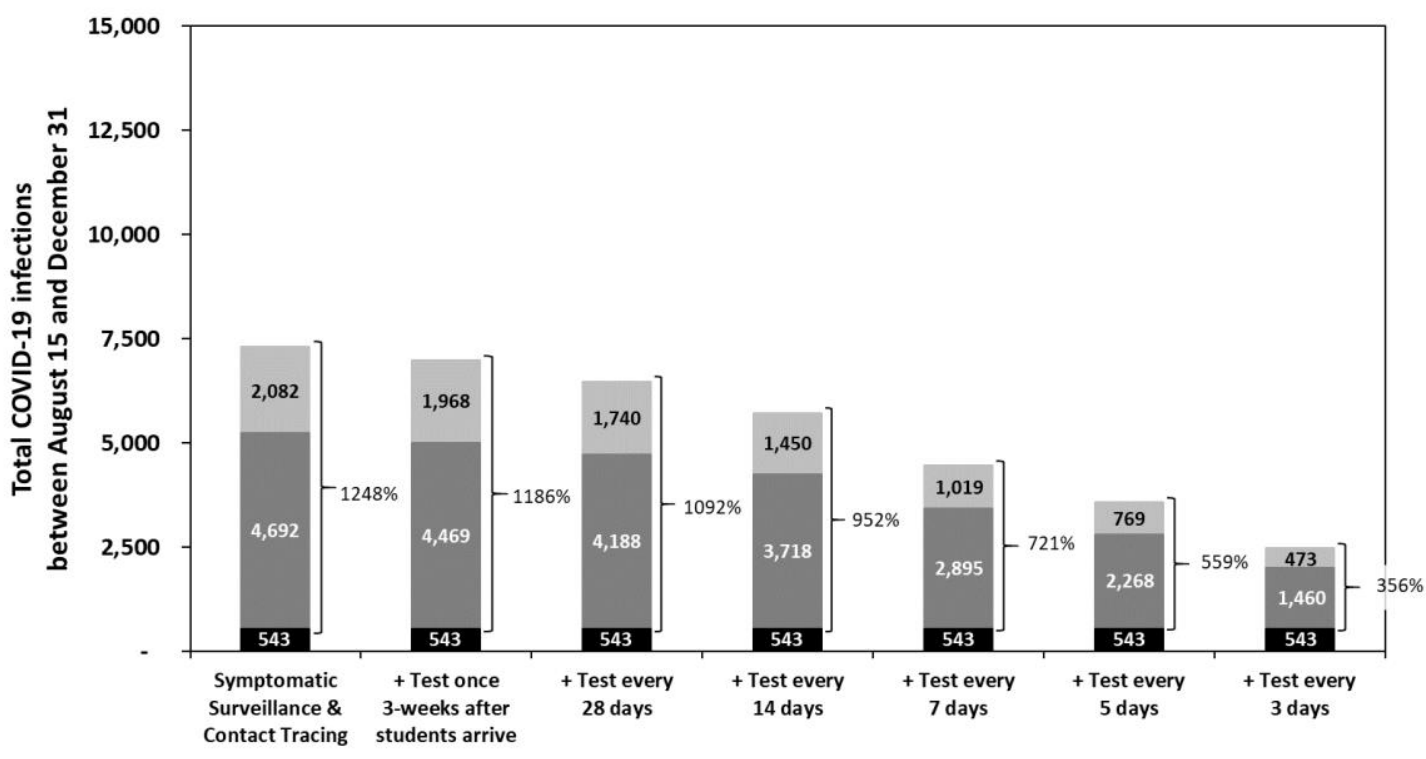




\section{TABLE 1. Base case parameters and sources. Mean and $95 \%$ confidence interval representing the} uncertainty in the mean used in sensitivity analysis.

\begin{tabular}{|c|c|c|}
\hline Parameter & Mean and $95 \% \mathrm{Cl}$ & Reference \\
\hline \multicolumn{3}{|l|}{ Contact structure } \\
\hline \multicolumn{3}{|l|}{ General population } \\
\hline General population & 12.21 & Calculated 36 \\
\hline University students & 0.38 & Calculated 36 \\
\hline Long-term care residents & 0.1 & Calculated \\
\hline \multicolumn{3}{|l|}{ University students } \\
\hline General population (includes faculty, staff, and graduate students) & $9.5(5.0,15.0)$ & Calculated 40,41 \\
\hline University students & $14.2(10.0,28.4)$ & Calculated 40,41 \\
\hline Long-term care residents & 0 & Assumed \\
\hline \multicolumn{3}{|l|}{ Long-term care residents } \\
\hline General population (includes LTC staff) & $14.2(11.4,17.0)$ & 38,39 \\
\hline University students & 0 & Assumed \\
\hline Long-term care residents & $19.9(11.3,28.5)$ & 38 \\
\hline \multicolumn{3}{|l|}{ Infectiousness and COVID-19 prevention behaviours } \\
\hline RO: Average number of new infections per infection & $3.0(2.85,3.3)$ & Empirically estimated a \\
\hline $\begin{array}{l}\text { Reduction in contacts when aware of infected status and in-home } \\
\text { isolation }\end{array}$ & $90 \%(80 \%, 95 \%)$ & Assumed \\
\hline Reduction in contacts when in hospital & $100 \%$ & Assumed \\
\hline $\begin{array}{l}\text { Effectiveness of mask wearing, reduction in transmission during a close } \\
\text { contact between a susceptible and an infected person }\end{array}$ & $40 \%$ & 43 \\
\hline \multicolumn{3}{|l|}{ General population } \\
\hline Initial proportion who are 'high-intensity physical distancers' & $50 \%$ & 46 \\
\hline \multicolumn{3}{|l|}{ High-intensity physical distancer } \\
\hline Reduction in contacts & $75 \%$ & 46 \\
\hline Mask wearing & $86 \%$ & 46 \\
\hline \multicolumn{3}{|l|}{ Low-intensity physical distancers / Unable to reduce contacts } \\
\hline Reduction in contacts & $0 \%$ & Assumed \\
\hline Mask wearing & $38 \%$ & 46 \\
\hline \multicolumn{3}{|l|}{ University students } \\
\hline Initial reduction in contacts & $24 \%$ & 46 \\
\hline Mask wearing & $57 \%$ & 46 \\
\hline \multicolumn{3}{|l|}{ Response to COVID-19 community outcomes } \\
\hline \multicolumn{3}{|l|}{$\begin{array}{l}\text { General population increase participation in high-intensity physical } \\
\text { distancing }\end{array}$} \\
\hline COVID-19 patients in critical care exceeds 15 & $0.5 \%$ per day & Assumed \\
\hline COVID-19 deaths in the past 10 days exceeds 10 & $1 \%$ per day & Assumed \\
\hline $\begin{array}{l}\text { Maximum level of participation in high-intensity physical } \\
\text { distancing }\end{array}$ & $80 \%$ & Assumed \\
\hline \multicolumn{3}{|l|}{ University students increase reduction in contacts } \\
\hline COVID-19 patients in critical care exceeds 15 & $0.5 \%$ per day & Assumed \\
\hline COVID-19 deaths in the past 10 days exceeds 10 & $1 \%$ per day & Assumed \\
\hline Maximum level of contact reduction & $50 \%$ & Assumed \\
\hline \multicolumn{3}{|l|}{ Time to diagnosis } \\
\hline $\begin{array}{l}\text { Minimum time from symptom onset to clinical presentation (average } \\
\text { days) }\end{array}$ & $2.1(1,3)$ & \\
\hline \multicolumn{3}{|l|}{$\begin{array}{l}\text { Daily probability of diagnosis by symptom-based surveillance and } \\
\text { contact tracing, general population and student population }\end{array}$} \\
\hline Symptomatic cases & $15.8 \%$ & Calculated ${ }^{b}$ \\
\hline Asymptomatic cases & $4.1 \%$ & Calculated ${ }^{b}$ \\
\hline Sensitivity of nasopharyngeal swab PCR test for COVID-19 & $72.1 \%$ & 51,52 \\
\hline
\end{tabular}


medRxiv preprint doi: https://doi.org/10.1101/2020.09.18.20197467; this version posted September 18, 2020. The copyright holder for this preprint (which was not certified by peer review) is the author/funder, who has granted medRxiv a license to display the preprint in perpetuity.

It is made available under a CC-BY-NC-ND 4.0 International license .

Long-term care residents

Asymptomatic

Symptomatic, cared for in long-term care

Hospitalized, no critical care resources

Critical, requires mechanical ventilation (MV)

Critical, requires renal replacement therapy (RRT)

University students

Asymptomatic

Mild or Moderate

Severe

Critical, requires MV

Critical, requires RRT

General population

Asymptomatic

Mild or Moderate

Severe

Critical, requires MV

Critical, requires RRT

Time to health event transition (Meanf, days)

Average duration of infectiousness

Incubation period: Exposure $\rightarrow$ Symptom onset

Infectiousness prior to symptom onset

Diagnosis: Symptom onset $\rightarrow$ First opportunity for diagnosis

Symptom onset $\rightarrow$ Progression to severe or critical symptoms

Severe symptoms: In hospital $\rightarrow$ Recovery or Death

Critical care: MV in ICU $\rightarrow$ Post-ICU in hospital or Death

Critical care: Post-ICU $\rightarrow$ Recovery

Critical: RRT $\rightarrow$ Discharge or Death

Symptomatic in LTC: Symptom onset $\rightarrow$ Recovery or Death

Clinical improvement in patients receiving lower level of care than is medically indicated

Severe symptoms: Home isolation $\rightarrow$ Recovery

\section{Mortality}

Long-term care residents

Symptomatic, cared for in long-term care

Hospitalized, no critical care resources

Critical, requires MV

Critical, requires RRT

University students

Mild or Moderate

Severe (In hospital)

Critical, requires MV

Critical, requires RRT

General population

Mild or Moderate

Severe (In hospital)

Critical, requires MV

Critical, requires RRT

\author{
$12 \%(1.2 \%, 22.6 \%)$ \\ $76.2 \%$ \\ $11.4 \%(9 \%, 14 \%)$ \\ $0.3 \%(0,0.7 \%)$ \\ $0.1 \%(0,0.2 \%)$ \\ $31 \%(18 \%, 80 \%)$ \\ $67.8 \%$ \\ $1.0 \%(0.5 \%, 1.5 \%)$ \\ $0.18 \%(0,0.4 \%)$ \\ $0.06 \%(0,0.1 \%)$ \\ $31 \%(26 \%, 37 \%)$ \\ $60.4 \%$ \\ $3.75 \%(2.0 \%, 8.0 \%)$ \\ $1.25 \%(1.0 \%, 1.8 \%)$ \\ $0.45 \%(0.2 \%, 0.7 \%)$
}

$10(6.3,16.0)$

$5.6(5.1,6.1)$

$2.5(2.0,3.0)$

$2.1(1.1,3.1)$

$5.8(4,8)$

$8.3(6,12)$

$18.7(10,32)$

$10.1(6,18)$

$30.3(12,44)$

$18.0(14,24)$

$18.0(14,24)$

$25.5 \%(21 \%, 30 \%)$

$47.4 \%(34 \%, 60 \%)$

$70.8 \%$ (66\%, 75\%)

$74.9 \%(67 \%, 83 \%)$

$0 \%$

$0.43 \%(0.1 \%, 0.7 \%)$

$21.5 \%(17 \%, 25 \%)$

$35.9 \%(26 \%, 46 \%)$

$0 \%$

$14.4 \%(4 \%, 33 \%)$

$42.9 \%(41 \%, 45 \%)$

$53.4 \%(50 \%, 57 \%)$
61,62

Calculated

35

35

Estimated $c$

63

Calculated

Estimated d

64

Estimated ${ }^{c}$

63

Calculated

Calibrated

64

Estimated c

$4,5,31,32$
30
$4,31,32$
7
33
33
34
34
34

Estimated in calibration

Assumed

$$
35
$$

35

Based on outcomes in $\geq 70$ year olds ${ }^{34}$

Based on outcomes in $\geq 70$ year olds 34

Estimated non-ICU mortality for $<55$ year olds 33

Based on outcomes in 16 to 39 year olds 34

Based on outcomes in 16 to 39 year olds ${ }^{34}$

Assumed

Estimated non-ICU mortality for $<75$ year olds 33

Based on outcomes in $<70$ year olds ${ }^{34}$

Based on outcomes in $<70$ year olds $34,65,66$ 
medRxiv preprint doi: https://doi.org/10.1101/2020.09.18.20197467; this version posted September 18, 2020. The copyright holder for this preprint (which was not certified by peer review) is the author/funder, who has granted medRxiv a license to display the preprint in perpetuity.

It is made available under a CC-BY-NC-ND 4.0 International license .

Mortality in patients unable to receive medically indicated care Case fatality rate, Severe patient requiring hospitalization, In home isolation

$25 \%(16 \%, 35 \%)$
$40 \%(21 \%, 60 \%)$

Daily rate, Patients who need MV or RRT, In home isolation

Daily rate, Patients who need MV or RRT, In hospital

$60 \%(41 \%, 80 \%)$
Assumed

Assumed, 2-day life expectancy Assumed, 1-day life expectancy

a. Using exponential regression, we empirically estimated the basic reproduction number, $\mathrm{R}_{0}$, the average number of secondary infections produced by one infected individual during the infected individual's entire infectious period assuming a fully susceptible population, is 3.0 based on Ontario's reported cases between March 7 to March $22 .{ }^{42}$

b. The observed median time to diagnosis through symptom-based surveillance alone of 4.6 days $(95 \% \mathrm{Cl}: 4.2,5.0)$ and symptom-based surveillance in combination with contact tracing efforts of 2.9 days $(95 \% \mathrm{Cl} 2.4,3.4)$ in Shenzhen, China. ${ }^{49}$ From this, we estimated that symptom-based surveillance and contact tracing results in a daily probability of diagnosis of $15.8 \%$ and the daily probability of detection from contact tracing of $4.1 \%$ in asymptomatic infections.

c. Among critical care patients, we estimate the ratio of patients requiring renal replacement therapy (RRT) to mechanical ventilation (MV) based on the UK Intensive Care National Audit and Research Centre (ICNARC) report describing the care and outcomes of 10,118 critical care COVID-19 patients in the UK. In this report, 7,277 patients required MV and 2,673 required RRT, resulting in a ratio of 0.37 RRT patients per mechanical ventilation patient. ${ }^{34}$

d. In Canada, based on 63,800 COVID cases in people who were not residents of long-term care facilities reported between February 23 and June 21, 20.3\% of hospitalized patients received critical care; ${ }^{35}$ this is also consistent with rates of critical care observed in the UK (22\% overall hospitalized patients go to ICU). ${ }^{33}$ Therefore, we estimate the ratio of 3.92 hospitalized without critical care patients per critical care patient.

e. Initially estimated using the same process as is described in footnote d. Adjusted in calibration process to better fit the observed data (see Supplemental Methods).

f. Median and IQR presented in the cited primary work were transformed to Mean $(95 \% \mathrm{CI}$ range) assuming a gamma distribution. 
TABLE 2. Infections averted in the general population with 5-day testing and one-time testing of students compared to a policy of no routine asymptomatic testing (symptom-based surveillance and contact tracing only). Scenarios vary the proportion of infections in the student population that are asymptomatic and timing and level of students contact reductions. We calculate the expected number of critical care admissions averted and COVID-19 deaths averted to be $1.7 \%$ and $1.32 \%$ of general population infections averted which includes hospitalizations and deaths which may occur after December 31 to all individuals infected prior to December 31.

\begin{tabular}{|c|c|c|c|c|c|c|c|c|c|c|}
\hline \multirow[b]{2}{*}{ Scenario } & \multirow[b]{2}{*}{$\begin{array}{l}\text { Without } \\
\text { students }\end{array}$} & \multirow[b]{2}{*}{$\begin{array}{l}\text { With } \\
\text { students }\end{array}$} & \multicolumn{4}{|c|}{ 5-day testing compared to no routine testing } & \multicolumn{4}{|c|}{$\begin{array}{l}\text { One-time testing three weeks after student } \\
\text { arrival compared to no routine testing }\end{array}$} \\
\hline & & & $\begin{array}{l}\text { Infections } \\
\text { averted }\end{array}$ & $\begin{array}{l}\text { \% averted } \\
\text { in the } \\
\text { general } \\
\text { pop'n }\end{array}$ & $\begin{array}{l}\text { Critical care } \\
\text { adm'n } \\
\text { averted }\end{array}$ & $\begin{array}{l}\text { COVID-19 } \\
\text { deaths } \\
\text { averted }\end{array}$ & $\begin{array}{l}\text { Infections } \\
\text { averted }\end{array}$ & $\begin{array}{l}\text { \% averted } \\
\text { in the } \\
\text { general } \\
\text { pop'n }\end{array}$ & $\begin{array}{l}\text { Critical care } \\
\text { adm'n } \\
\text { averted }\end{array}$ & $\begin{array}{l}\text { COVID-19 } \\
\text { deaths } \\
\text { averted }\end{array}$ \\
\hline \multicolumn{11}{|l|}{$31 \%$ asymptomatic in students } \\
\hline $\begin{array}{l}\text { Base case physical distancing ( } 24 \% \\
\text { reduction in contacts immediately) }\end{array}$ & 3,900 & 7,299 & 1,392 & $70 \%$ & 16.5 & 12.8 & 127 & $81 \%$ & 1.8 & 1.4 \\
\hline $\begin{array}{l}\text { Two weeks of } 2.0 x \text { activity among } \\
\text { students, followed by } 24 \% \text { reduction in } \\
\text { contacts }\end{array}$ & 3,900 & 10,294 & 2,661 & $64 \%$ & 29.1 & 22.6 & 361 & $66 \%$ & 4.0 & 3.1 \\
\hline $\begin{array}{l}\text { Low level of physical distancing ( } 15 \% \\
\text { reduction in contacts immediately) }\end{array}$ & 3,900 & 11,209 & 3,448 & $61 \%$ & 35.9 & 27.9 & 91 & $64 \%$ & 1.0 & 0.8 \\
\hline $\begin{array}{l}\text { Two weeks of } 2.0 x \text { activity among } \\
\text { students, followed by } 24 \% \text { reduction in } \\
\text { contacts; } 60 \% \text { of general population } \\
\text { engaged in high-intensity physical } \\
\text { distancing }\end{array}$ & 543 & 7,317 & 3,737 & $65 \%$ & 41.0 & 31.8 & 337 & $66 \%$ & 3.8 & 2.9 \\
\hline \multicolumn{11}{|l|}{$50 \%$ asymptomatic in students } \\
\hline $\begin{array}{l}\text { Base case physical distancing ( } 24 \% \\
\text { reduction in contacts immediately) }\end{array}$ & 3,900 & 7,445 & 1,533 & $70 \%$ & 18.2 & 14.2 & 175 & $81 \%$ & 2.4 & 1.9 \\
\hline $\begin{array}{l}\text { Two weeks of } 2.0 x \text { activity among } \\
\text { students, followed by } 24 \% \text { reduction in } \\
\text { contacts }\end{array}$ & 3,900 & 10,582 & 2,931 & $65 \%$ & 32.4 & 25.1 & 414 & $67 \%$ & 4.7 & 3.7 \\
\hline \multicolumn{11}{|l|}{$80 \%$ asymptomatic in students } \\
\hline $\begin{array}{l}\text { Base case physical distancing ( } 24 \% \\
\text { reduction in contacts immediately) }\end{array}$ & 3,900 & 7,524 & 1,603 & $69 \%$ & 18.8 & 14.6 & 40 & $68 \%$ & 0.5 & 0.4 \\
\hline $\begin{array}{l}\text { Two weeks of } 2.0 x \text { activity among } \\
\text { students, followed by } 24 \% \text { reduction in } \\
\text { contacts }\end{array}$ & 3,900 & 10,889 & 3,209 & $65 \%$ & 35.3 & 27.4 & 337 & $60 \%$ & 3.4 & 2.7 \\
\hline
\end{tabular}




\section{REFERENCES}

1. Sanche S, Lin YT, Xu C, Romero-Severson E, Hengartner N, Ke R. High Contagiousness and Rapid Spread of Severe Acute Respiratory Syndrome Coronavirus 2. Emerg Infect Dis 2020;26.

2. Riou J, Althaus CL. Pattern of early human-to-human transmission of Wuhan 2019 novel coronavirus (2019-nCoV), December 2019 to January 2020. Euro Surveill 2020;25.

3. Li Q, Guan X, Wu P, et al. Early Transmission Dynamics in Wuhan, China, of Novel CoronavirusInfected Pneumonia. N Engl J Med 2020.

4. He X, Lau EHY, Wu P, et al. Temporal dynamics in viral shedding and transmissibility of COVID19. Nat Med 2020.

5. Tindale L, Coombe M, Stockdale JE, et al. Transmission interval estimates suggest presymptomatic spread of COVID-19. medRxiv 2020:2020.03.03.20029983.

6. Michelen M, Jones N, Stavropoulu C, On behalf of the Oxford COVID-19 Evidence Service Team. In patients of COVID-19, what are the symptoms and clinical features of mild and moderate cases? : Centre for Evidence-Based Medicine, Nuffield Department of Primary Care Health Sciences, University of Oxford. [Accessed: April 1, 2020] Available at: https://www.cebm.net/covid-19/in-patients-of-covid-19what-are-the-symptoms-and-clinical-features-of-mild-and-moderate-case/.

7. Gaythorpe K, Imai N, Cuomo-Dannenburg G, et al. Report 8: Symptom progression of COVID-19. Imperial College London COVID-19 Response Team 2020.

8. Grasselli G, Zangrillo A, Zanella A, et al. Baseline Characteristics and Outcomes of 1591 Patients Infected With SARS-CoV-2 Admitted to ICUs of the Lombardy Region, Italy. JAMA 2020.

9. Cummings MJ, Baldwin MR, Abrams D, et al. Epidemiology, clinical course, and outcomes of critically ill adults with COVID-19 in New York City: a prospective cohort study. Lancet 2020;395:1763-70.

10. The College Crisis Initiative at Davidson College. C2i Data Dashboard [Last updated: August 21, 2020]. [Accessed August 23, 2020]. Available at: https://collegecrisis.shinyapps.io/dashboard/.

11. US Centers for Disease Control and Prevention. Considerations for Institutions of Higher Education May 30, 2020. [Accessed: August 23, 2020]. Available at:

https://www.cdc.gov/coronavirus/2019-ncov/community/colleges-universities/considerations.html.

12. Holmes EC, Ghedin E, Halpin RA, et al. Extensive geographical mixing of 2009 human H1N1 influenza A virus in a single university community. J Virol 2011;85:6923-9.

13. Glatt AE, Jacobson SH, MacNeil J, Myers A, Turner JC, Vassallo A. College campus outbreaks require timely public health response. Infectious diseases in children 2015;October.

14. Uchida M, Tsukahara T, Kaneko M, Washizuka S, Kawa S. How the H1N1 influenza epidemic spread among university students in Japan: experience from Shinshu University. Am J Infect Control 2012;40:218-20.

15. Guh A, Reed C, Gould LH, et al. Transmission of 2009 pandemic influenza A (H1N1) at a Public University--Delaware, April-May 2009. Clin Infect Dis 2011;52 Suppl 1:S131-7.

16. Mitchell T, Dee DL, Phares CR, et al. Non-pharmaceutical interventions during an outbreak of 2009 pandemic influenza A (H1N1) virus infection at a large public university, April-May 2009. Clin Infect Dis 2011;52 Suppl 1:S138-45. 
17. Nierenberg A, Pasick A. Schools Briefing: University Outbreaks and Parental Angst. . The New York Times August 19, 2020. Available at: https://www.nytimes.com/2020/08/19/us/colleges-closingcovid.html.

18. Knight V. College Professors Made Models Showing How Bad COVID-19 Would Be on Campus. Some Administrators Ignored Them. September 15, 2020. Available at: https://time.com/5889032/campus-coronavirus-models/.

19. Fausset R. Outbreaks Drive U.N.C. Chapel Hill Online After a Week of Classes. The New York TImes August 17, 2020.

20. Paltiel AD, Zheng A, Walensky RP. Assessment of SARS-CoV-2 Screening Strategies to Permit the Safe Reopening of College Campuses in the United States. JAMA Netw Open 2020;3:e2016818.

21. Cashore JM, Duan N, Janmohamed A, et al. COVID-19 Mathematical Modeling for Cornell's Fall Semester. June 15, 2020. Available at: https://datasciencecenter.cornell.edu/research/covid-19mathematical-modeling-for-cornells-fall-semester/.

22. Lopman B, Liu C, Le Guillou A, et al. A model of COVID-19 transmission and control on university campuses. medRxiv 2020:2020.06.23.20138677.

23. Brooks-Pollock E, Christensen H, Trickey A, et al. High COVID-19 transmission potential associated with re-opening universities can be mitigated with layered interventions. medRxiv 2020:2020.09.10.20189696.

24. Elbanna A, Wong GN, Weiner ZJ, et al. Entry screening and multi-layer mitigation of COVID-19 cases for a safe university reopening. medRxiv 2020:2020.08.29.20184473.

25. University of Illinios at Urbana-Champaign. On-campus COVID-19 testing. [Accessed September 11, 2020]. Available at: https://covid19.illinois.edu/health-and-support/on-campus-covid-19-testing/.

26. Binkley C. Colleges plan for coronavirus testing, but strategies vary. WCVB News. . July 26, 2020. [Accessed September 11, 2020]. Available at: https://www.wcvb.com/article/colleges-plan-forcoronavirus-testing-but-strategies-vary-widely/33426361\#.

27. Cornell University. COVID-19 and Reactivation Planning: Surveillance Testing. [Accessed September 11, 2020] Available at: https://covid.cornell.edu/testing/surveillance/.

28. Harvard University. Coronavirus Testing \& Tracing: Unobserved Self-Administered Testing [Accessed: September 11, 2020] Available at: https://www.harvard.edu/coronavirus/testingtracing\#unobserved.

29. Du Z, Wang L, Cauchemez S, et al. Risk for Transportation of 2019 Novel Coronavirus Disease from Wuhan to Other Cities in China. Emerg Infect Dis 2020;26.

30. Lauer SA, Grantz KH, Bi Q, et al. The Incubation Period of Coronavirus Disease 2019 (COVID-19) From Publicly Reported Confirmed Cases: Estimation and Application. Ann Intern Med 2020.

31. Wolfel R, Corman VM, Guggemos W, et al. Virological assessment of hospitalized patients with COVID-2019. Nature 2020.

32. To KK, Tsang OT, Leung WS, et al. Temporal profiles of viral load in posterior oropharyngeal saliva samples and serum antibody responses during infection by SARS-CoV-2: an observational cohort study. Lancet Infect Dis 2020. 
It is made available under a CC-BY-NC-ND 4.0 International license .

33. Docherty AB, Harrison EM, Green CA, et al. Features of 20133 UK patients in hospital with covid-19 using the ISARIC WHO Clinical Characterisation Protocol: prospective observational cohort study. BMJ 2020;369:m1985.

34. Intensive Care National Audit \& Research Centre. ICNARC report on COVID-19 in critical care [July 17, 2020]. Available at: https://www.icnarc.org/Our-Audit/Audits/Cmp/Reports. 2020.

35. Statistics Canada. Detailed preliminary information on confirmed cases of COVID-19 (Revised), Public Health Agency of Canada. Table: 13-10-0781-01. [Accessed July 20, 2020]. Available at: https://www150.statcan.gc.ca/t1/tbl1/en/cv.action?pid=1310078101.

36. Prem K, Cook AR, Jit M. Projecting social contact matrices in 152 countries using contact surveys and demographic data. PLoS Comput Biol 2017;13:e1005697.

37. Najafi M, Laskowski M, de Boer PT, Williams E, Chit A, Moghadas SM. The Effect of Individual Movements and Interventions on the Spread of Influenza in Long-Term Care Facilities. Med Decis Making 2017;37:871-81.

38. Champredon D, Najafi M, Laskowski M, Chit A, Moghadas SM. Individual movements and contact patterns in a Canadian long-term care facility. AIMS Public Health 2018;5:111-21.

39. Roberts AR, Ishler KJ, Adams KB. The Predictors of and Motivations for Increased Family Involvement in Nursing Homes. The Gerontologist 2018;60:535-47.

40. Beutels $P$, Shkedy Z, Aerts $M$, Van Damme P. Social mixing patterns for transmission models of close contact infections: exploring self-evaluation and diary-based data collection through a web-based interface. Epidemiol Infect 2006;134:1158-66.

41. Edmunds WJ, O'Callaghan CJ, Nokes DJ. Who mixes with whom? A method to determine the contact patterns of adults that may lead to the spread of airborne infections. Proc Biol Sci 1997;264:94957.

42. Ontario Ministry of Health and Long-Term Care. COVID-19 case data. [Accessed August 26, 2020] Available at: https://covid-19.ontario.ca/data.

43. Mitze T, Kosfeld R, Rode J, Wälde K. Face Masks Considerably Reduce Covid-19 Cases in Germany. IZA Discussion Paper Series No 13319 Bonn, Germany: IZA Institute of Labour Economics 2020;Available at: https://www.iza.org/publications/dp/13319/face-masks-considerably-reduce-covid19-cases-ingermany-a-synthetic-control-method-approach:2020.06.21.20128181.

44. Zhang J, Litvinova M, Liang Y, et al. Changes in contact patterns shape the dynamics of the COVID-19 outbreak in China. Science 2020.

45. Webster R, Brooks S, Smith L, Woodland L, Wessely S, Rubin J. How to improve adherence with quarantine: Rapid review of the evidence. medRxiv 2020:2020.03.17.20037408.

46. Angus Reid Institute. COVID-19 Compliance: One-in-five Canadians making little to no effort to stop coronavirus spread. August 17, 2020. Available at: http://angusreid.org/covid-compliance/.

47. Care in Canadian ICUs. Canadian Institute for Health Information (CIHI). 2016.

48. London Health Sciences Centre. Critical Care readiness: Expanding nursing staff to support COVID-19. [Accessed September 16, 2020]. Available at: https://www.Ihsc.on.ca/news/critical-carereadiness-expanding-nursing-staff-to-support-covid-19.

49. Bi Q, Wu Y, Mei S, et al. Epidemiology and transmission of COVID-19 in 391 cases and 1286 of their close contacts in Shenzhen, China: a retrospective cohort study. Lancet Infect Dis 2020;20:911-9. 
It is made available under a CC-BY-NC-ND 4.0 International license .

50. Herhalt C. Blood tests indicate one per cent of Ontario's population had COVID-19. CTV News. August 3, 2020. [Accessed September 11, 2020] Available at: https://toronto.ctvnews.ca/blood-testsindicate-one-per-cent-of-ontario-s-population-had-covid-19-1.5049457.

51. Kucirka LM, Lauer SA, Laeyendecker O, Boon D, Lessler J. Variation in False-Negative Rate of Reverse Transcriptase Polymerase Chain Reaction-Based SARS-CoV-2 Tests by Time Since Exposure. Ann Intern Med 2020;173:262-7.

52. Carver C, Jones N. Comparative accuracy of oropharyngeal and nasopharyngeal swabs for diagnosis of COVID-19. Centre for Evidence-Based Medicine 2020;Available at: https://www.cebm.net/covid-19/comparative-accuracy-of-oropharyngeal-and-nasopharyngeal-swabsfor-diagnosis-of-covid-19/.

53. Ontario Ministry of Health and Long-Term Care. COVID-19 Testing for Long-Term Care Home Staff. . July 16, 2020. [Accessed: August 26, 2020]. Available at: http://www.health.gov.on.ca/en/pro/programs/ltc/memo 20200716.aspx.

54. Tingle S. Winter term will be online: Provost's letter. McMaster University September 14, 2020. [Accessed September 17, 2020] Available at: https://covid19.mcmaster.ca/winter-term-will-be-onlineprovosts-letter/.

55. Lopez G. Close the bars. Reopen the schools. Vox. July 1, 2020. [Accessed September 16, 2020]. Available at: https://www.vox.com/future-perfect/2020/7/1/21306816/coronavirus-pandemic-reopenschools-economy-social-distancing.

56. Singer N. College Quarantine Breakdowns Leave Some at Risk. The New York Times. . September 9, 2020. [Accessed September 11, 2020]. Available at: https://www.nytimes.com/2020/09/09/business/colleges-coronavirus-dormitories-quarantine.html.

57. Chang K. A University Had a Great Coronavirus Plan, but Students Partied On. The New York Times September 10, 2020. [Accessed: September 12, 2020] Available at:

https://www.nytimes.com/2020/09/10/health/university-illinois-covid.html.

58. Lazzerini M, Barbi E, Apicella A, Marchetti F, Cardinale F, Trobia G. Delayed access or provision of care in Italy resulting from fear of COVID-19. Lancet Child Adolesc Health 2020.

59. The Korean clusters. Reuters Graphics Updated March 20, 2020. [Accessed April 15, 2020]. Available at: https://graphics.reuters.com/CHINA-HEALTH-SOUTHKOREACLUSTERS/0100B5G33SB/index.html.

60. Giuffrida A, Beaumont P. Coronavirus: inquiry opens into hospitals at centre of Italy outbreak. . The Guardian February 26, 2020. Available at: https://www.theguardian.com/world/2020/feb/26/coronavirus-inquiry-opens-into-hospitals-at-centreof-italy-outbreak.

61. Roxby AC, Greninger AL, Hatfield KM, et al. Outbreak Investigation of COVID-19 Among Residents and Staff of an Independent and Assisted Living Community for Older Adults in Seattle, Washington. JAMA Intern Med 2020.

62. Kimball A, Hatfield KM, Arons M, et al. Asymptomatic and Presymptomatic SARS-CoV-2 Infections in Residents of a Long-Term Care Skilled Nursing Facility - King County, Washington, March 2020. MMWR Morb Mortal Wkly Rep 2020;69:377-81.

63. Buitrago-Garcia DC, Egli-Gany D, Counotte MJ, et al. Asymptomatic SARS-CoV-2 infections: a living systematic review and meta-analysis [Version 3]. medRxiv 2020:2020.04.25.20079103. 
medRxiv preprint doi: https://doi.org/10.1101/2020.09.18.20197467; this version posted September 18, 2020. The copyright holder for this preprint (which was not certified by peer review) is the author/funder, who has granted medRxiv a license to display the preprint in perpetuity.

It is made available under a CC-BY-NC-ND 4.0 International license .

64. Poletti P, Tirani M, Danilo C, et al. Probability of symptoms and critical disease after SARS-CoV-2 infection [Version 2]. arXivorg Cornell University June 22, 2020. Available at: https://arxiv.org/abs/2003.09320.

65. Metnitz PG, Krenn CG, Steltzer $\mathrm{H}$, et al. Effect of acute renal failure requiring renal replacement therapy on outcome in critically ill patients. Crit Care Med 2002;30:2051-8.

66. Brivet FG, Kleinknecht DJ, Loirat P, Landais PJ. Acute renal failure in intensive care units--causes, outcome, and prognostic factors of hospital mortality; a prospective, multicenter study. French Study Group on Acute Renal Failure. Crit Care Med 1996;24:192-8. 